\title{
Negros e indios en el obraje de San Ildefonso. Real Audiencia de Quito. 1665-1666
}

\author{
por \\ Jean-Pierre Tardieu \\ Université de La Réunion
}

\begin{abstract}
El espacio concentracionario de los obrajes textiles del mundo andino colonial exacerbó las tensiones entre los trabajadores indigenas y los esclavos negros. Haciendo caso omiso de la legislación protectora emitida a favor de los naturales, los dueños se valieron de la inversión de los valores sociales admitida por muchos y de la sed de compensación suscitada por las frustraciones de la esclavitud, que hacian de los indios los "esclavos de los esclavos», para transformar a los negros de los obrajes en verdaderos matones serviles. Estudiaremos los mecanismos del sistema y sus consecuencias en la segunda mitad del siglo XVII a través del caso del obraje de San Ildefonso, situado cerca de Ambato, en el Ecuador actual.
\end{abstract}

Palabras Clave: Ecuador; obrajes; siglo XVII; indios; negros.

Los obrajes coloniales de Hispanoamérica merecieron la atención de los estudiosos por su impacto económico y social ${ }^{1}$. Uno de los más destacados, el historiador ecuatoriano Federico González Suárez, hizo hincapié en el papel que desempeñaban en la jurisdicción de la Real Audiencia de Quito, en relación con todas las provincias del virreinato del Perú, desde el Nuevo Reino de Granada hasta las minas de Potosí adonde llegaban los paños «de la tierra» tejidos en sus telares².

Por generar estas estructuras de producción un despiadado sistema de explotación del indio, considerado como mero instrumento de trabajo, la Corona, teniendo en cuenta los informes de los responsables religiosos ${ }^{3}$, se vio

\footnotetext{
1 Silva Santisteban, 1964. Salas de Coloma, 1979, 1998.

2 González Suárez, 1970. Rueda Novoa, 1988. Miño Grijalva, 1991: 76-97.

3 Véase más abajo.
} 
obligada a imponer normas de protección para limitar los efectos de la codicia de los obrajeros, lo cual patentiza la gravedad de la situación. En 28 de mayo de 1621 condenó Felipe IV los excesos de poder cometidos por los encomenderos que se valían de los indios encomendados para trabajar en obrajes: «no se permita que los Encomenderos tengan obrajes dentro de sus encomiendas, ni tan cerca de ellas que se pueda rezelar que ocuparán a los Indios en servicios personales, y se aprovecharán indebidamente de sus bienes, y servirán de sus personas, hijos, y mugeres» ${ }^{4}$. En 22 de noviembre de 1621 decidió el mismo soberano que los obrajeros no pudiesen acudir a la mita para reclutar mano de obra gratuita: «por ningún caso se haga mita, ni repartimiento de Indios para él [el obraje], y hagan que esté continuamente abierto, para que entren, y salgan los Indios a su voluntad, y por ningún caso se les pueda impedir: y no los obliguen a que trabajen involuntarios ${ }^{5}$. La Real Cédula de 11 de junio del mismo año les impuso a los oidores la visita de los obrajes para castigar los excesos que sufrían los indios ${ }^{6}$. Los considerandos del capítulo 40 de la Instrucción impartida a los virreyes en 1628 no dejan lugar a dudas en cuanto a la determinación de la Corona: «Los excesos cometidos en los obrages de paños, y otros texidos y labores han llegado a tanto extremo, por los impedimentos, que resultan contra la libertad de los Indios». No se podría fundar obrajes sin permiso del mismo Consejo de Indias $^{7}$. A estos textos se referirá el procurador de los dominicos de Quito para el caso de San Ildefonso que vamos a contemplar más abajo.

En el periodo de los acontecimientos que vamos a comentar, el alcalde del crimen de la Real Audiencia de Lima, Juan de Padilla, denunció, en un memorial dirigido a la Corona el 20 de julio de 1657, los daños que sufrían los indios de los obrajes. El documento pone de realce lo ineficaz de la legislación anterior. Se despachó una Real Cédula el 21 de septiembre de 1660 que exigía la formación en Lima de una junta, compuesta por el virrey, conde de Alba, el arzobispo, los oidores y Juan de Padilla, con la finalidad de estudiar el memorial. En 14 de julio de 1664, emitió el virrey conde de Santisteban la Ordenanza de Obrajes para remediar los excesos cometidos en estos establecimientos. Los indios mitayos destinados a las labores, de más de doce años, no podrían pasar de la quinta parte en Quito y turnarían cada seis meses. Con la misma periodicidad los corregidores tendrían que visitar los obrajes con el cura del lugar y el protector de los indios. Y se fijaban los jornales corres-

\footnotetext{
4 Recopilación de Leyes de los Reynos de las Indias, 1998, t. 2: 267.

5 Ibidem, Libro IIII, Título XXVI, Ley II, t. 2: 107.

6 Ibidem, Libro II, Título XXXI, Ley XIIII, t. 1: 484.

7 Ibidem, Libro IIII, Título XXVI, Ley I, t. 2: 106.
} 
pondientes a las diversas tareas. Esta Ordenanza, es de pensar, tuvo repercusiones en el caso del obraje de San Ildefonso, en el reino de Quito ${ }^{8}$.

Sin embargo no se consiguió mejorar las cosas y no faltaron los incendios de obrajes, que no todos serían accidentales, como el del obraje de Guano en 1712 en la jurisdicción de Riobamba, perteneciente al mismo presidente del Consejo de Indias, duque de Úceda9 .

Pero poco se ha dicho sobre las tensiones en estos lugares entre los esclavos negros y los trabajadores indígenas, aunque no faltan las referencias en los informes dirigidos a la Corona. Por ello proponemos en las líneas siguientes contemplar este aspecto, tomando como centro de interés, a principios de la segunda mitad del siglo XVII, el obraje de San Ildefonso, sito en el partido de Ambato, donde dichas tensiones se insertaron en un ambiente conflictivo que suscitó una amplia encuesta de parte de la Real Audiencia de Quito en contra de un personaje de no poca monta, el general don Antonio Pérez de Galarza, encomendero y gobernador de Pelileo ${ }^{10}$. Este caso es excepcional por enfocar las tensiones entre siervos y naturales a partir de los testimonios de los propios indios del obraje que pertenecían a los pueblos vecinos de Pelileo y Patate.

\section{ConteXtualización}

Desde los principios de la colonia, la jurisdicción de Riobamba, donde se sitúa el partido de Ambato, se destacó por su abundante ganado menor ${ }^{11}$. Si nos atenemos a las cifras presentadas por Jaime Costales Peñaherrera, existían en la época estudiada 65 obrajes, de los cuales 39 pertenecían a particulares ${ }^{12}$.

8 Vargas Ugarte, 1966: 299-302.

9 Archivo General de la Nación del Ecuador (A.G.N.E.), sección Obrajes, caja 18. En realidad no era tan fácil acusar a los indios, dado que los obrajes eran sumamente peligrosos, con pailas en los talleres de tintorería y tejados de paja que se inflamaban con la menor chispa avizada por el soplo de los vientos. Así que, casi siempre, no se podía ir más allá de sospechas de venganza.

${ }^{10}$ La documentación explotada a continuación se encuentra en A.G.N.E., sección Obrajes, caja 4, expte 1; caja 7, expte 1; caja 9, expte 3 . Antes de la encuesta que vamos a evocar, las quejas de los indios de San Ildefonso llegaron al rey, quien reprendió a los oidores de la Real Audiencia de Quito por su permisividad. La Corona ordenó en 1663 la destrucción del obraje, lo cual no se cumplió. Véase: Ortiz de la Tabla Ducasse, 1993: 221-223.

11 Terán Najas, Pazmiño, Gómez, Rueda, 2000: 32. Alcedo, 1967: 307-308. Ortiz de la Tabla, 1977: 51. Tyrer, 1976: 16.

12 Costales Peñaherrera, 1975: 12 y 17. Al lado de los obrajes de particulares había los de las comunidades indias. 
El mayor obraje, situado en Riobamba, pertenecía a un propietario ausentista, el duque de Úceda, y empleaba a 782 mitayos que alternaban en sus talleres ${ }^{13}$. El obraje de San Ildefonso, que nos interesará en estas líneas, empleaba de 200 a 300 trabajadores entre indios y negros ${ }^{14}$.

\section{La mano de obra en los obrajes: esclavos negros versus indios}

Entre los lugares donde corría más riesgo el indígena, con la complicidad tácita de los dueños, se encontraban los obrajes, por constituir un sistema concentracionario, a diferencia de las haciendas, donde se encerraba a los productores en espacios vigilados. Suscitaba tensiones la coexistencia de negros y naturales en estas unidades de producción. Como sabemos, al poco tiempo de acabarse la conquista, no dejaron de plantear problemas en todas las Indias occidentales las relaciones entre indígenas y esclavos, particularmente con el desarrollo del recurso a la mano de obra servil, consecuencia de la legislación protectora de los indios ${ }^{15}$.

Algunos pensadores, para explicar la dominación de los naturales por los esclavos negros evocaron la mentalidad india, como el dominico fray Reginaldo de Lizárraga (1539-1609): «Parece realmente son de su naturaleza para servir: a los negros esclavos reconocen superioridad, llamándolos señores, con saber comprados y vendidos, y lo que les mandan obedecen muy mejor que lo mandado por nosotros» ${ }^{16}$. Acertó fray Reginaldo en la medida en que solo el miedo a los negros experimentado por los indios explicaba su comportamiento. Los esclavos - de muy superficial formación cristiana, insistían los responsables religiosos - no tenían ningún escrúpulo, y, de tenerlo, lo acallara su sed de compensación. La cita da a entender por qué los dueños hacían la vista gorda. Fray Miguel Agia, en Servidumbres personales de Indios (1603), evocó precisamente la situación en los obrajes e ingenios de Nueva España:

donde están [los indios] como en galera el tiempo que les dura el trabajar en los dichos ingenios y obrajes, particularmente los que trabajan de las puertas adentro donde les tienen encerrados debaxo de llave, y donde trabajan en compañía de negros, que es lo peor que a los indios se puede dar, pues donde trabajan juntos, el peso del trabajo cahe y carga sobre los miserables indios sin remedios, y los

13 Burgos G., 1957: 362.

14 Tyrer, 1976.

15 Tardieu, 1990; 2000.

16 Descripción breve de toda la tierra del Perú, Tucumán, Río de la Plata y Chile para el Excmo. Sr. Conde de Lemos y Andrade, presidente del Consejo Real de Indias, Los Cronistas de Convento, 1920: 151. 
dueños gustan dello porque quieren que se mueran antes diez indios, que un negro, que les costó su dinero ${ }^{17}$.

Esta era efectivamente la razón: el mantenimiento de los indios mitayos, empleados en las minas, los obrajes y las haciendas, no les costaba mucho a los españoles, por llegar los naturales de sus pueblos con ropa y víveres. No pasaba igual con los negros, cuyo valor alcanzaba a veces precios altísimos en relación con su estado físico y sus conocimientos técnicos. A estos sí que tenían que proveerles de lo necesario... a no ser que encontrasen medios para no cumplir, como veremos. Estos son elementos que no perderemos de vista para entender la situación en San Ildefonso.

Para una época posterior a nuestro marco temporal, o sea el 15 de octubre de 1695, en su informe sobre los obrajes de la provincia, el fiscal de la Real Audiencia de Quito, afirmando que «los negros esclavos dominan en esta miserable gente», emitió un juicio muy pesimista sobre la situación de los trabajadores indígenas: «... frecuentemente reducidos a peor esclavitud que la de los Negros, pues a estos los sustentan, bisten, y curan sus amos por su presio; pero como los yndios mueren por su cuenta, y en su lugar an de entrar otros de nada se cuida menos» ${ }^{18}$.

Claro que no había obstáculo alguno cuando la mano de obra era enteramente esclava. Fue el caso del establecimiento de seis telares que poseían el maestre de campo Francisco de Cevallos y su mujer, doña Isabel de Andagoya y Otalosa, en el valle de Iñaquito, donde labraban quince esclavos negros y mulatos, que vendieron a censo al convento de Santo Domingo de Quito, más precisamente a favor de la capilla y capellanía de San José19.

\section{Evolución contradictoria de la legislación}

Debido a las protestas que suscitó la presencia de naturales al lado de esclavos en estas unidades de producción y en los ingenios de caña de azúcar, la Corona intentó prohibirla, como consta de la Real Cédula dirigida el 24 de noviembre de 1601 al virrey Luis de Velasco:

Otrosy porque he sido ynformado quel trabajo que los yndios han padecido y padecen en los obrages de paños e yngenios de azucar es muy grande y excesivo y contrario a salud y causa de que se ayan consumido y acauado en el muchos,

\footnotetext{
17 Agia, 1964: 64.

18 A.G.N.E., sección Obrajes, caja 15, expte. 1.

19 A.G.N.E., sección Obrajes, caja 13, expte. 9.
} 
prohibo y expresadamente defiendo y mando que de aqui adelante en ninguna prouincia ni parte de esos rreynos puedan trauajar ni trauajen los yndios en los dichos obrajes de paños de españoles ni en los yngenios de açucar lino lana seda o algodon ni en cosa semejante aunque los españoles tengan los dichos obrages e yngenios en compañia de los mismos yndios sino que los españoles que los quisieren tener, aunque sea en compañia de los yndios o en otra qualquier manera los ayan de beneficiar con negros u otro genero de seruicio [...] y mando que asi se cumpla precisamente sin embargo de qualesquier leyes ordenanças cedulas y prouisiones que en contrario desto esten dadas que si necesario es por la presente las reboco $^{20}$.

Dado lo difícil que hubiera sido sustituirles enteramente por negros, siguieron trabajando los indios en los obrajes. Valga el ejemplo de la región de Ambato. A media legua del pueblo, Rodrigo Venegas poseía por los años 1604-1605 un obraje cuya mano de obra se componía de negros y de algunos indios $^{21}$. En el informe transmitido el 4 de abril de 1604, el presidente Miguel de Ibarra informó que se habían fundado dos obrajes en la villa de Riobamba con licencia del virrey. El uno pertenecía a un vecino encomendero llamado Lorenzo de Cepeda y el otro era de Alonso de Guadalupe, tratante. El primero empleaba a algunos esclavos negros, aunque la mayor parte de los trabajadores eran indios. En el segundo, se intentaba «meter los negros que pudiere $»^{22}$. Disfrutaron el mismo permiso en 1606 Fernando de Cevallos en Machangara-Iñaquito, y en 1607 Diego Valencia León en Callo, Diego de Niebla en Santa Bárbara y María de la Plaza en San Diego ${ }^{23}$.

De este modo la cédula de 1601 quedó letra muerta. Según los datos recogidos por K. J. Andrien, entre 1601 y 1628, la Corona habría dado 38 permisos para que los obrajeros pudiesen acudir al trabajo forzoso, viéndose obligados numerosos indios a laborar en los obrajes para pagar su tributo. El obraje de San Ildefonso, en Ambato, en que prestaban sus servicios más de 400 naturales, tenía licencia para disfrutar de mano de obra esclava ${ }^{24}$.

En los años posteriores, con las quejas que seguían llegando al Consejo de Indias acerca de la coexistencia de los indios y de los negros en las unidades de producción, las licencias para meter negros en los obrajes fueron más difíciles de obtener. Los propietarios tuvieron que lograr el beneplácito del mismo virrey, como aparece en un documento de 1627. Gaspar Jiménez de Barrionuevo, alguacil mayor del partido de Riobamba, le suplicó al mar-

\footnotetext{
20 Levillier, 1921.

21 Levillier, 1921: 57.

22 Archivo General de Indias, Sevilla, Audiencia de Quito 9, R. 7, N. 52, 1, fol. 2v.

23 Villalba, 8 (Quito, 1986): 79-80. Soasti Toscano, 1986.

24 Brines Tyrer, 1976: 153. Andrien, 1995: 58, 26.
} 
qués de Guadalcázar que le diese licencia para poner una cantidad de negros esclavos suyos en un obraje que poseía en el partido. El virrey lo remitió al presidente de Quito, quien ya había dado su visto bueno. Al fin y al cabo, en 5 de marzo de 1627, se dejó convencer Guadalcázar de que el proyecto no originaría dificultades en la medida en que los indios que servían en dicho obraje eran muchachos sin la debida formación para acudir a los oficios de tejedores y cardadores. Tomó muy en cuenta el parecer del presidente, Antonio de Morga, quien apoyó la petición de Jiménez de Barrionuevo, «con que los dichos negros esclavos esten y travajen divididos y apartados de los yndios que acudiesen al dicho obraje y no se mescle los unos con los otros de modo que los dichos yndios no recivan agravios, vejaciones y malos tratamientos de los dichos negros esclavos» ${ }^{25}$.

Fuera lo que fuere, no faltan ejemplos en la documentación de la presencia de esclavos negros en los obrajes. El 30 de agosto de 1652, por ejemplo, Diego Rodrigues, maestro de obraje, se querelló en contra de Pedro Ruiz de Rojas, acusándole de haberse quedado con tres esclavos suyos, Bentura, Pablo y Pedro, de la época en que ambos eran socios de la misma compañía, ocupándoles como oficiales en su obraje ${ }^{26}$. El 27 de noviembre de 1668, dos madres indígenas se querellaron en contra de doña Magdalena Eugenia de Larraspuru y Vera ${ }^{27}$, dueña del obraje Nuestra Señora de Atocha, sito en el asiento de Ambato. Con el fin de reclutar indios para sus talleres, utilizaba el miedo que inspiraban sus esclavos ${ }^{28}$. No era casual el recurso a esclavos para ese propósito, como lo señalamos en otro estudio ${ }^{29}$.

\section{El obraje De SAn ILDEFOnSo}

\section{Formación del obraje}

Las escrituras notariales de Cuenca arrojan luz sobre la formación de este obraje. Se refieren a Pedro Vallejo, vecino de la villa de Villar Don Pardo, o sea Riobamba, y natural de la provincia de Burgos en España. Estuvo casado

25 A.G.N.E., sección Obrajes, caja 8.

26 A.G.N.E., sección Obrajes, caja 3, expte 1.

27 Magdalena Eugenia de Larraspuru era hija de doña María Vera Mendoza, de quien hablaremos más tarde, y de su primer marido don Juan Bautista Larraspuru. Don José Antonio López de Galarza fue su padrastro. Se casó con el general don Francisco Villagómez, corregidor de Riobamba. Ortiz de la Tabla Ducasse, 1993: 245-246.

28 A.G.N.E., Quito, sección Obrajes, caja 8.

29 Para los valles del Cuzco en el siglo XVIII. Tardieu, 2000: 116. 
en primeras nupcias con Juana de Padilla, hija de vecinos de Quito, quien le trajo una dote de 835 cabezas de ovejas de Castilla, 34 vacas y 48 caballos. Viudo, se casó de nuevo con doña María de Araujo, hija del capitán Alonso Peñafiel y de Lorenza de Araujo que le dieron una dote de 1000 pesos. Formó una primera compañía con su yerno Alonso de Guadalupe Espinosa para comprar 10000 ovejas, y luego un obraje de paños en el sitio de San Ildefonso, término del pueblo de Pelileo. Una cláusula de la escritura preveía que los esclavos comprados con el dinero de Vallejo y de su yerno pasarían, después de los ocho años que duraría la compañía, al dicho Espinosa por el dinero que hubiesen costado. Con 4000 pesos que le dieron ambos socios, el mercader Mateo de Arroyo, de partida a Portobelo, les trajo 14 esclavos, negros y negras angolas, que costaron 290 pesos cada uno. Luego compraron otros 30 esclavos, también angolas, a 450 pesos. Según afirmó en su testamento, con fecha de 8 de junio de 1627, Vallejo gastó mucho dinero para que aprendiesen los oficios del obraje. Acabada la compañía y muerto su yerno, se quedaron en poder de sus herederos, quienes vendieron el obraje y los siervos a Juan de Vera Mendoza. El comprador, según Vallejo, abonó una cantidad que iba entre 550 y 600 pesos por cada uno de ellos, lo cual era por supuesto mucho dinero, de ahí la protesta del testador, quien se estimó engañado en más de 3000 pesos. La formación técnica adquirida en el obraje explicaría la importante plusvalía de estos trabajadores serviles ${ }^{30}$. Este dato no carece de interés ya que prueba que ciertos dueños se mostraban dispuestos a pagar una buena cantidad de dinero para prescindir en la medida de lo posible de la mano de obra indígena, dadas las medidas de protección de que gozaban de parte de las autoridades ${ }^{31}$. Veremos más abajo que los negros de San Ildefonso no dejaron de plantear problemas a los herederos de Juan de Vera Mendoza.

\section{Situación en 1665-1666}

Por casamiento de la heredera en segundas nupcias, doña María de Vera y Mendoza, el obraje pasó a manos del general don Antonio López de Galarza, encomendero y gobernador de Pelileo, uno de los miembros más esclarecidos de los grupos de poder de Quito ${ }^{32}$, quien se valió de su doble condición

\footnotetext{
30 Archivo Histórico del Azuay (Cuenca), Ecuador, Notaría tercera, libro 502.

31 Tardieu, 2006: 309-311.

32 Entre 1611 y 1639 los más ilustres encomenderos criollos de Quito, emparentados entre sí eran don Diego de Sandoval, don Francisco Villacís, don Cristóbal Núñez de Bonilla
} 
para pasar la legislación por alto. Según las declaraciones recogidas del procurador general de los dominicos, fray Pedro de la Barrasa, su padre había puesto a su disposición los indios de su encomienda. Fallecida su esposa, pasó López de Galarza de administrador a propietario del obraje y con la muerte de su padre, se aprovechó de la encomienda para encontrar mano de obra.

San Ildefonso era un complejo económico que, además de la unidad de producción textil con sus diferentes «cuartos» o talleres, abarcaba una hacienda, un cañaveral y un trapiche movido por bueyes. La hacienda de Chumaquí, distante media legua, producía el mantenimiento de los negros: trigo, maíz, cebada y papa. En el cañaveral trabajaban indios concertados durante el tiempo de la molienda, cortando caña y acarreándola al trapiche, llamado San Antonio. No se ocupaban de la elaboración del azúcar, reservada a negros moledores y azucareros.

En cuanto a los negros del obraje, su número difiere según las declaraciones. Nos atendremos a la memoria que pidió el oidor Merlo de la Fuente, encargado de la encuesta, a Cristóbal López de Noboa, maestro de labrar paños, el 27 de enero de 1666. Suministró datos que recoge el cuadro siguiente:

\begin{tabular}{|l|c|c|c|c|c|c|}
\hline & $\begin{array}{c}\text { Niños } \\
0-5 \text { años }\end{array}$ & $\begin{array}{c}\text { Niñas } \\
0-5 \text { años }\end{array}$ & Hombres & Mujeres & T1 & $\%$ \\
\hline Bozales & & & 6 & 4 & 10 & 11,11 \\
\hline Criollos & 5 & 2 & 38 & 33 & 78 & 86,66 \\
\hline Mulatos & & & 1 & 1 & 2 & 2,22 \\
\hline T2 & 5 & 2 & 45 & 38 & 90 & \\
\hline$\%$ & 7,77 & 50 & 42,22 & & \\
\hline
\end{tabular}

La gran mayoría de los esclavos eran criollos, posiblemente hijos de los angolas bozales comprados por los dueños anteriores. Buena parte de ellos estarían arraigados en el obraje, en la medida en que su trabajo, a diferencia de los negros de hacienda, requería una gran especialización. El desequilibrio entre los sexos no era muy fuerte, debido quizá al deseo de estabilizar a la mano de obra servil.

Se habían formado familias, y la presencia de 7 criollitos aseguraría el relevo con el tiempo. Pero no se les dejaba a las madres el tiempo de criar a su progenie: eran indias asalariadas las que le servían de nodrizas. María

y don Juan López de Galarza. Entre 1655 y 1657, ocupó la plaza de capitán de caballería don José Antonio López de Galarza y llegó a ser general. Ortiz de la Tabla Ducasse, 1993: 146. 
Sumasancta declaró haber criado una negrilla «porque la negra madre suya hilaba en el obraje». Por supuesto no era su única ocupación: también cocinaba para los galpones, o sea para los cuartos donde trabajaban indios y negros. Otra, Luisa Imisinguil, dijo que en siete años había criado siete negritos y negritas de López de Galarza, quien le debía 105 pesos a 15 pesos por cada crianza. Pero hasta el momento de su declaración solo había recibido 2 sombreros de un valor de 6 pesos, 2 anacos azules, o sea faldas que iban hasta la rodilla (16 pesos), 2 varas de jerga (1 peso 4 reales), 2 fanegas de maíz (4 pesos), 4 fanegas de cebada (2 pesos), 2 reales de sal, 2 de raspaduras, todo a doblado precio, 2 pesos cada año en plata, 1 real de chicharrones, 3 reales de pan. Al presente tenía dos crías y «yendo a pedir que le paguen la envían aoramala».

Varios de los indios que efectuaron su declaración en el mes de diciembre de 1665 afirmaron que «trabajan los dichos yndios con los negros de dicho obraxe entreverados». Los testimonios suministran algunas cifras, aunque no exhaustivas, sobre la presencia de indios y negros en los diferentes «cuartos»: tejedores: 21 indios; galpón de los cardadores: 11 indios; hiladores: 6 indios e indias y muchachos; corredor o casa: 5 indios; tundiduria: 6 indios; percha: 2 negros; y batán: 2 negros.

\section{Las querellas}

Las quejas que llegaban a la Real Audiencia, desde hacía tiempo ya, preocupaban al presidente y a los oidores. En 17 de noviembre de 1665, obviamente como consecuencia de la publicación de la Ordenanza de obrajes de 1664 evocada más arriba, nombraron a uno de ellos, don Luis Joseph Merlo de la Fuente, oidor y alcalde de corte, para investigar acerca de los agravios de que padecían los indios de San Ildefonso. Según Jaime Costales Peñaherrera en su estudio sobre el obraje citado más arriba, el número de indios que habían trabajado para Galarza ascendía a 1518 personas entre 1619 y 1665 , a quienes se les debía la cantidad de 15185 pesos 3 reales 3 tomines, cuentas que fueron presentadas en Quito el 3 de noviembre de $1666^{33}$.

Efectivamente una de las quejas más recurrentes de los indios concernía a su salario y los maltratos que se les infligían. Domingo Pailsacín, nacido en el obraje, nunca cobró algo por su trabajo, e iba «pasando una galera como si fuera esclabo, azotandolo cruelmente, sin tener libertad de su persona ni conocer socorro de sustento y estar el, su mujer e hijos pereciendo».

33 Ortiz de la Tabla Ducasse, 1993: 146-148. 
En cuanto a los maltratos, afirmó Gaspar Tapobanda, se buscaba como pretexto el menor descuido en el trabajo para «darles de varazos en la cauesa y espaldas con baras de membrillo». Vuelve sin cesar la evocación de los azotes. Uno de los indios afirmó haber sido «aporreado en rostro con cuernos de venado». Volveremos más abajo a estas violencias, por ser los negros los instrumentos de los castigos.

Don Juan Machuca, indio principal y fiscal del pueblo de Pelileo, no se contentó con esgrimir argumentos parecidos, sino que puso énfasis en los procedimientos empleados por el obrajero para reclutar gañanes. Sus mayordomos y recogedores, y en particular un indio a quien nombró como alcalde del obraje, se llevaron treinta muchachos fuera de los que ya estaban en el establecimiento, quitándoles de su familia y de la enseñanza religiosa que se les impartía en la doctrina. Los indios encerrados de modo ilegal alcanzaban la cifra de ochenta individuos ${ }^{34}$.

Fray Pedro de la Barrasa, procurador de los dominicos, denunció una situación que iba en contra de la ley. El obraje era de negros, según lo dispuesto en su fundación, y por este motivo contaba con más de 130 piezas de esclavos ${ }^{35}$. Ahora bien, con los indios de Pelileo y de otros pueblos vecinos, la mano de obra alcanzaba la cifra de 300 personas. Era el resultado de la no aplicación de la legislación que preveía que un encomendero no podía tener obrajes ni haciendas en su encomienda. El presidente Vásquez de Velasco en primero de septiembre de 1661, auto confirmado por la Real Audiencia, significó a López de Galarza la prohibición de usar a sus indios encomendados en el obraje y de mezclar en él indios con negros. Protestó también el fraile en contra de la petición del dueño de transformar la capilla del obraje en anexo de la iglesia de Pelileo. A su parecer no la motivó el celo por los indios, sino el deseo de impedir su salida del obraje para ir a misa y doctrina a Pelileo. Y no podía argüir el dueño que sus esclavos carecían de pasto espiritual, ya que desde su fundación el coadjutor de cura de Pelileo iba a decir misa al obraje cada domingo y fiesta de guardar para ellos, los mayordomos y los amos por 200 pesos anuales, pagados fielmente. Amén de esto, desde que el dominio del establecimiento pasó a López de Galarza, crecieron los maltratos y los agravios de que eran víctimas los indios «que violentamente y con mano de encomendero a metido para que le sirban en el dicho obraje». Y por si fuera poco, también recurrió a mitayos y gañanes ${ }^{36}$.

Según órdenes del oidor Merlo de la Fuente, el alguacil de la visita, Bartolomé Valencia, efectuó el 27 de enero de 1666 el embargo de los esclavos

\footnotetext{
34 A.G.N.E., sección Obrajes, caja 4, expte. 1.

35 Nótese la diferencia con la cifra conseguida por el oidor.

36 A.G.N.E., sección Obrajes, caja 4, expte. 1; caja 9, expte. 3.
} 
y les puso en poder del maestro de labrar paño Cristóbal López Novoa, quien les tendría en depósito. El 6 de mayo, el alguacil llevó a seis de ellos a la cárcel de Ambato, donde estarían a disposición del oidor. Se trataba de cinco hombres de entre veinte y doce años y de una chica de doce años. Con el producto de su venta, se puede deducir, se pagarían los salarios debidos por López de Galarza a los indios.

Nuestro enfoque no es insistir en estos datos, sino ver cómo se insertaban los esclavos negros en este contexto y cuáles eran los agravios cometidos por ellos en contra de los naturales.

\section{ReLaCiOnes InTERÉTNICAS EN SAN ILDEFonso}

Sevicias impuestas por los esclavos dentro de la unidad de producción

Si nos atenemos a los testimonios de la encuesta dirigida por Merlo de la Fuente, el comportamiento de los esclavos negros del obraje para con los indígenas no difería del que denunciaron los informes evocados más arriba. Hecho significativo, se apoderaban de su «cocabi» ${ }^{37}$, o sea la escasa comida que los gañanes y voluntarios traían consigo cada mañana, compuesta de tortillas y de maíz tostado. Fue lo que declaró Lorenzo Maenzín el 24 de diciembre de 1665 , y sus dichos nos permiten imaginar con qué miedo llegaban estos trabajadores. La baja de rendimiento que suscitaban estos robos, por debilitamiento físico, acarrearía, a no caber duda, severos castigos impartidos por los maestros de obraje, sin que les preocupara indagar sobre los motivos. No vacilaban los esclavos, los días de fiesta, en imponer a los indios la limpieza no solo de los cuartos de trabajo sino también de sus propios galpones. El 10 de diciembre, Lázaro Quispe resultó muy explícito acerca de estos maltratos, aludiendo a los que padeció su propio hijo, cuatro meses atrás, al acabar de cumplir el año de gañán en el trapiche de San Antonio. Como se había dormido durante la molienda, los tres esclavos del trapiche le cogieron, le quitaron los calzones y, tendiéndole en el suelo, le dieron con un freno más de cincuenta azotes en las nalgas. A la madre, esposa de Lázaro, quien presenció los hechos e intentó protestar, uno de ellos, llamado Hernandillo, le dio un puñetazo en la cara, tratándole de «puta».

Bien sabían los esclavos que el dueño no se inmutaría por esto, ya que usaba esta inversión de valores para sacar el mayor provecho de los indígenas. viaje.

37 El «cocaví», del quecha Kokavi, correspondía a las provisiones de víveres para un 
¿No escogía entre ellos a los caporales encargados de castigar a los gañanes que no respetaran las normas de trabajo? Transformados en instrumentos de coerción, les parecería del todo normal a estos esclavos lograr una ventaja de su situación que les permitiera compensar de algún modo las desgracias de la esclavitud. A decir verdad, el mismo amo no se metía en esto, cediendo el sitio a sus maestros de obraje, como denunció Gaspar Tapobanda el 13 de diciembre de 1665. Bien sabía de lo que estaba hablando por llevar este testigo 23 años trabajando en el obraje. Su declaración no dejó lugar a dudas en cuanto a los criterios de gestión de Cristóbal López de Noboa, contratado como maestro dos años antes. Como caporales de los indios, escogió a dos esclavos, Draguillo e Ignacio, con el pretexto de que no se podía confiar semejante responsabilidad a indios por apiadarse estos de sus congéneres. Los esclavos no experimentaban ninguna compasión por los oficiales que no respetaban las normas, dándoles varazos en la cabeza y las espaldas con varas de membrillo. A Draguillo e Ignacio también les conoció Lorenzo Canín, según dijo el 16 de diciembre. Se portaban como verdaderos cómitres:

...dixo que no todos los negros del dicho obraxe hazen agrauios a los yndios que trabajan en el y que los que lo hazen son aquellos que nombran por capitanes los maestros para que hagan trauajar apriessa y que acauen pronto las tareas y las hagan bien hechas, porque de por si sin intervención del maestro andan recorriendo las salas de los hiladores, rompedores y ymprimidores y quando les paresse que no estan bien hechas, o que no se dan prisa hazen tender a los officiales y los açoten a seis y a doze açotes...

Los castigos los aplicaban también los caporales, aseveró otro testigo, con cuero torcido, «duro como garrote», con las puntas quemadas. Los indios les habían dado el apodo de «el barroso», «el valiente». A uno de ellos que había huido, fueron tantos los azotes que se le dieron en dos ocasiones que se cansaron cuatro negros, mudándose de dos en dos. Pasaron de ciento cada vez, y después se le lavaron las heridas con orines.

Se entiende entonces cómo unos negros pasaron de la coerción a la criminalidad. Al intentar los indios oponer alguna resistencia a los hurtos de los esclavos, estos contestaban con puñetazos y coces, añadió Lorenzo Maenzín.

Pero lo peor fue el asesinato de un indio por Zaruma, evocado en varias declaraciones, y en particular por Tomás Sumunsún el 20 de diciembre de 1665. El nombre del criminal revelaría sus orígenes. Procedería del pueblo de Zaruma, donde las minas del «cerro de oro» requerían mano de obra servil, aunque en la época, la producción había bajado. Quizá por este motivo, se le habría vendido fuera, de ahí su insatisfacción y su rebelión en contra de las normas impuestas en el obraje. Se dio a la huida, transformándose en cimarrón 
de poca monta porque no tardaron en ponerle la mano encima. Con grillos en los pies, le encerraron en el calabozo, donde mató a un indio, llamado Francisco Yunapauta. Se refirieron varios testigos al crimen, aunque de una manera confusa, por no recordar con exactitud los hechos ya antiguos. Agustín Chaygua, del pueblo de Pelileo, sabía que «con la compañía de los negros del dicho obraxe a resultado muertes de yndios». El día siguiente, o sea el 12 de diciembre de 1665, un coterráneo suyo, Pedro Togta, suministró más información al respecto. Murió Francisco, oriundo de la parte de Guambahalo de dicho pueblo de Pelileo, de una puñalada dada por Zaruma con un huso. Ahorcaron al criminal junto a la capilla. Lázaro Quispe admitió el 10 de diciembre que se había enterado del asesinato ocurrido mucho tiempo atrás. No estuvo presente en el momento de los hechos, pero la víctima era de la misma parcialidad que él. Por lo menos pudo ver la herida que se situaba en la barriga. Los parientes del difunto pidieron castigo e hicieron ahorcar al culpable, pero no se acordaba si fue en Ambato o en el mismo obraje. Lo de que sí estaba seguro era que vio la cabeza del asesino en un árbol cerca de la puerta del establecimiento. Los recuerdos de Lorenzo Canín fueron menos vagos el 16 de diciembre porque pudo ver a la víctima que murió «a hora de misa mayor». A su parecer, los hechos remontaban a veinte años, más o menos. Zaruma le dio con el huso en la barriga al indio solo porque este se levantó una mañana diciendo el «alabado», lo cual lo puso «rabioso». Al negro le ahorcaron junto a la capilla, poniendo su cabeza en un sauce cerca de la puerta del obraje.

No dejaron de pedir a López de Galarza su versión, haciendo hincapié en su responsabilidad por mezclar indios con negros en el calabozo. Zaruma, furioso por encontrarse preso, no pudo aguantar que, al despertar, le dijera el indio «Alabado sea el Santísimo Sacramento del Altar». Intentó el obrajero explicar que, a la sazón, todavía no estaba casado con su mujer, la cual era viuda de su primer marido. A la dueña del obraje le informó una carta del teniente de gobernador de Ambato. Según sabía, fue casual lo ocurrido no en la cárcel sino en el callejón que separaba el obraje de los negros de los cuartos en que trabajaban los indios. Dispuso que ahorcasen al negro. Luego le hicieron cuartos y pusieron su cabeza en una picota para escarmiento de sus compañeros. Concluyó su declaración añadiendo «con que si mato tambien murio, con que satisfizo». No podía aceptar que se mudasen las circunstancias, «no siendo el caso originado de estar juntos en el calabozo».

Merece este crimen un breve comentario. ¿Cómo explicar la reacción de Zaruma frente a un saludo tan inocente e incluso tan benévolo? ¿Habría que relacionarla con algún odio racial? La única razón valedera sería la desespe- 
ranza de Zaruma, quien no aceptaba la servidumbre impuesta por el sistema esclavista. Fracasaron sus intentos de encontrar de nuevo la libertad, lo cual le exasperó aún más. En semejante contexto, le puso fuera de sí el saludo por corresponder a lo que más odiaba, es decir, la hipocresía de la sociedad cristiana que se ufanaba de luchar por la libertad espiritual del hombre cuando le sumía en el cautiverio más despiadado tan solo por ser negro. Al fin y al cabo, nadie entendió la verdadera motivación del asesino. Bien mirado, el indio fue una víctima de sustitución: por no poder agredir Zaruma al lejano dueño esclavista, mató a uno de sus servidores que aceptaba pasivamente su condición. Fue la sumisión al sistema de explotación, manifestada por la salutación matutina, lo cual le puso «rabioso», como afirmaron algunos testigos. A esta violencia se vio reducido un hombre que ya no conseguía superar su desesperanza $^{38}$.

\section{Sevicias impuestas por los esclavos fuera de la unidad de producción}

Como los límites del obraje de San Ildefonso no les brindaban a los esclavos una posibilidad de compensación suficiente, la reproducción de la violencia pasaba de sus puertas Se aprovechaban de las oportunidades, verdaderas válvulas de escape, que les permitían externarla. Otra vez su comportamiento resultó similar a la actitud denunciada por los informes evocados más arriba, siendo el mercado o «gato» del pueblo de Patate, muy próximo al obraje, uno de los lugares de predilección de los esclavos para cumplir sus «exacciones», usando la indefensión de las vendedoras. Según don Pedro Mindalao, don Lázaro Tabalamba, don Fabián Huguina y don Andrés Llugsa, caciques del pueblo, se adueñaban a mojicones y coces de todo lo que las indias traían a vender. Cuando los pueblerinos estaban en la iglesia los domingos y días de fiesta, escuchando misa y asistiendo a doctrina, les hurtaban las frutas y las legumbres de sus huertas y las pocas pertenencias de sus ranchos, como las mantas. Últimamente, el día de Todos los santos, le robaron mucha caña a don Antonio Llugsa. Se intentó perseguir a los ladrones, pero

38 El caso de Zaruma se puede comparar con el de Luis de Venegas en 1727. Por su habilidad como minero, se le nombró a Venegas capitán de cuadrilla en las minas de oro de Micay, en la gobernación de Popayán, en la actual Colombia, que dependía a la sazón de la jurisdicción de la Real Audiencia de Quito. Altivo, no dejaba de recibir castigos, lo cual le incitó a darse al cimarronaje. Amenazaba a los indios, pronunciando blasfemias y «diciendo que no quería oir el nombre de Dios». Hecho preso, murió «bramando como un toro, echando espuma por la boca». Las sevicias le llevaron también al rechazo de la sociedad esclavista cristiana y por fin a un trastorno mental parecido al de Zaruma. Tardieu, 2006: 351-353. 
no se consiguió alcanzarles. Concluyeron su declaración los caciques con un tono patético: «...y nosotros como pobres yndios floxos no podemos pelear. Porque no nos maten, dexamos lleuar nuestras pobrezas tantos años, más de treinta años».

Algunas víctimas sin embargo sacaban fuerza de flaqueza, atreviéndose a quejarse ante el maestro de obraje al conseguir identificar a los delincuentes. Para Daniel Andagana, el negro Lorenzo «hera el que arranchaba de ordinario». Hacía dos meses, dos mujeres del pueblo fueron al obraje para protestar contra los abusos cometidos por los esclavos Juan y Lucas. Se hallaron en poder del primero unos manteles de los que habían hurtado a una de las indias. Pero no siempre podían llevar acusaciones precisas en contra de los culpables. El mismo testigo se refirió a su propio caso. Después de un robo efectuado en su casa, la única prueba de que los ladrones eran los negros fueron sus pisadas: «heran de patas grandes y tuertas que asi son las de los dichos negros». Agustín Yumiquinga nunca logró coger a los negros que le robaban el poco tabaco y los zapallos de su huerta. Cuando salía al oír el ruido, solo era para verles huir. No se trataba siempre de ladrones aislados sino de pandillas de chicos que podían alcanzar el número de veinte individuos. Resultaba difícil protegerse de estos robos en las chácaras, perpetrados a menudo de noche, aseguró don Juan Challay, alcalde y recogedor del obraje.

Resultaría fastidioso tratar de todos los casos evocados en la encuesta. Su redundancia patentiza la impunidad de que gozaban los esclavos negros de parte del dueño y de sus representantes en el obraje que se vieron obligados a explicarse. Permítasenos sin embargo no pasar por alto el amargo reparo de uno de los testigos, Ventura Cunamas, quien exclamó: «...pido y clamo ante Vmd como ante su Majestad para que desagrauie a todos los naturales yndios miserables que an estado captiuos aperreados entre negros enemigos nuestros en nuestra misma patria, y justicia.». Esta delación de una situación sumamente paradójica se inscribe en el contexto de la defensa de los indios iniciada por Bartolomé de las Casas y perseguida por la orden de los dominicos a que pertenecía fray Pedro de la Barrasa. Las declaraciones en contra de López de Galarza de parte del procurador de los frailes predicadores de Quito, fundamentadas en las relaciones del cura de Pelileo, son claros indicios de lo relevante de su papel en el asunto. 


\section{DEFENSA DE LOS RESPONSABLES}

\section{Evasivas de los maestros de labrar paños}

Se puso en tela de juicio la administración de los últimos maestros de obraje. Con ellos tenían que vérselas los gañanes e indios voluntarios que laboraban en el complejo de San Ildefonso. A ellos se quejaban de los excesos cometidos por los negros. Lo confuso de sus declaraciones durante la encuesta del oidor Merlo de la Fuente valoriza su malestar frente a las acusaciones sacadas de los testimonios.

En febrero de 1666, si Cristóbal López de Novoa no pudo negar que se nombraba a un negro como capitán de los esclavos del obraje, en cambio afirmó con vehemencia que no tenía nada que ver con los indígenas. Por si fuera poco, insistió, ni siquiera hubo indio caporal sino un «maestrillo, que como dicho tiene cuydado de que trabajen los yndios y de açotarlos en haciendo...». Francisco Rodríguez, que también estuvo de maestro en el obraje, tuvo que defenderse por no haberse opuesto a los hurtos de los negros en el gato, en los ranchos y en las chácaras de Pelileo los domingos y fiestas de guardar cuando los indios asistían a misa o a doctrina, y a los maltratos infligidos por los esclavos a los naturales si procuraban oponerse. La torpeza de su respuesta es reveladora: él cumplía con su deber que consistía estos días en comprobar que todos los negros fueran a misa, lo cual hacía llamándoles por padrón. Lo que pasaba después no era de su incumbencia. Sin embargo cuando los indios le informaban de las «bellaquerías» de los negros, no dejaba de castigar a los culpables. Pedro Núñez Monsalve adoptó la misma defensa. Corría a su cargo, en dichos días, el cuidar de que los negros asistiesen a doctrina y misa; pero, una vez salidos de capilla, no les volvía a ver hasta que reanudasen el trabajo el día siguiente. Al enterarse de que molestaban a las indias, les castigaba con azotes e incluso les tenía muchos días con hierros y grillos, con lo cual conseguía que no se desmandasen. En cuanto a Antonio de Soarnaba, contestó que, como administrador de San Ildefonso, no le correspondía asumir las obligaciones de los maestros. A ellos les tocaba vigilar a los esclavos que vivían en un galpón, puertas adentro. Cuando pasaba por el obraje, solo era para dirigirse a las haciendas por otros reparos tocantes a la administración.

Si no se atrevían a negar los hechos, contaban los responsables asalariados del complejo con estas evasivas para salir de apuros. Remitían de este modo a la máxima autoridad, la del dueño, quien pese a su posición social, tuvo que rendir cuentas. 
Tergiversaciones del dueño

Dada la gravedad del caso, a don Antonio López de Galarza le puso el oidor Merlo de la Fuente la ciudad por cárcel, lo cual, dado su rango, no era poca cosa. Su interrogatorio se efectuó a partir del 17 de febrero de 1666.

La pregunta 31 es de mucho peso por su formulación que procedía de las declaraciones de los testigos. Se le acusaba claramente de transformar a los esclavos en verdaderos instrumentos de coerción:

Preguntado como a hecho a los negros siendo esclavos verdugos de los indios dandoles mano a tanto desacuerdo a voluntad de los maestros solo porque fuesen horrorosos los castigos, no consintiendo que los yndios açotasen por decir que unos a otros por tenerse compasión no lo hacian bien.

El hipócrita irenismo de la respuesta pone de realce la mala fe del obrajero. Según sus alegaciones, las imputaciones en contra de los esclavos carecían de fundamento por el mero hecho de que estos consideraban a las indias como sus verdaderas madres por haber sido criados por ellas:

Dixo que los negros del dicho obraje an sido criados de las yndias hasta tener dos años y es tanto el amor que les tienen que no conocen mas madres y llaman a las que las parieron madrinas y para que los yndios fuesen castigados como dize este cargo auia de ser por mano de los mesmos que son tan crueles como faciles en no decir la verdad.

La explicación carece de rigor taxativo en la medida que un posible cariño experimentado por unos esclavos para con sus antiguas nodrizas no se opone forzosamente a la violencia en ciertas circunstancias, de parte suya o de otros. Para evadir sus responsabilidades, la táctica del obrajero consistió en acudir a una inversión de las acusaciones, como aparece en su respuesta al cargo 32 que le culpó de haber hecho de los indios esclavos de los esclavos, con motivo de imponer los negros la limpieza de su galpón a los naturales los domingos y días de fiesta cuando tenían que ir a misa. Otra vez la formulación del cargo corresponde a los lemas lascasanistas: «... y quedaron sin misa [los indios] por hazerlo no queriendo ellos [los negros] hazer lo que por esclavos les tocaba sino que los yndios por tenerlos por sus esclavos se los sirviesen». Los negros, contestó López de Galarza, se encargaban de la limpieza no solo de su galpón sino también de lo restante del obraje, y no tenían nada que les permitiera castigar a los indios como varas o bastones. Además no se quedaban los naturales en el obraje los domingos, salvo unos cuantos. Y cuando él se encontraba en el obraje le costaba harto trabajo obligarles a que asistieran a misa en el pueblo o en la capilla situada a veinte pasos. En cuanto a los 
improperios proferidos por los esclavos con respecto a algunas indias, como «putas», era una manera de responder a denuestos más graves. De cualquier modo, los mayordomos no permitían que los negros maltratasen a los indígenas en actos o en palabras. No vale la pena insistir en el descaro del obrajero, quien se atrevió a negarlo todo, dando a entender que el oidor había de elegir entre su versión y la de los indios. A todas luces intentaba imponer una relación de fuerza, contando con su prestigio y su poder para contrarrestar las acusaciones, hábilmente orquestadas por fray Pedro de la Barrasa.

En cuanto al asesinato de Francisco Yunapauta, según el cargo, el castigo impuesto por el obrajero al culpable no le eximía de su responsabilidad. Originó la desgracia el hecho de poner indios y negros en el mismo calabozo, a sabiendas de que estos de ordinario se beneficiaban de la indefensión de aquellos. Ya sabemos cómo se las arregló López de Galarza para obviar el cargo.

\section{La actuación del procurador de los dominicos}

Como tenemos dicho, el procurador de los dominicos condenó severamente la mala fe de López de Galarza. Demostró el fraile que la petición del obrajero para obligar a los indios a que asistiesen a misa en la capilla de su establecimiento era un falso pretexto para mejor controlarles. Tampoco podía argüir el dueño de la falta de pasto espiritual de sus esclavos cuando el cura de Pelileo solía ir a San Ildefonso para atenderles. Dicho esto, el fraile se demoró en las infracciones del gobernador relacionadas con la legislación vigente en materia de encomiendas. López de Galarza, al heredar la de su padre situada en Pelileo, siguió sirviéndose de los indios encomendados para proveer de trabajadores un obraje destinado por la licencia de fundación a acudir únicamente al trabajo de esclavos. Convenía pues devolver su libertad a los indios encerrados en el obraje, según las exigencias ya expresadas por la Real Audiencia al general López de Galarza, para que «no se siruiese de sus yndios en dicho obraje ni se mesclase con los negros y que los despoblase de dicho obraje y los redujiesen al dicho pueblo y les repartiesen sus tierras y que estuviesen y asistiesen a la doctrina cristiana». Había que reducirles con sus familias al pueblo donde vivirían «muy contentos por aber salido del cautiverio y esclavitud que pasaban». Huelga insistir en la dimensión lascasiana del discurso que determina el alcance del proceso. 


\section{La invisibilidad de los esclavos}

Al hojear los expedientes del caso, nos llamó la atención el hecho de que nunca se interrogó a los esclavos del obraje. El derecho castellano, en particular Las Siete Partidas, aunque consideraba a los siervos como bienes semovientes, y por lo tanto sin personalidad jurídica, nunca les negó la posibilidad de prestar testimonio, como prueba la voluminosa documentación archivística. Así que nos preguntaremos cómo explicar lo que bien podríamos calificar de invisibilidad de los negros de San Ildefonso, pese a lo reiterado de los reproches en su contra.

En este caso, no se les consideraría legalmente responsables de un comportamiento delictuoso, el cual corría a cargo de la potestad domínica encargada de controlar su actuación. No faltan las pruebas de que el obrajero manejaba su anhelo de compensación para mejor explotar a los naturales. Pero, y no se puede pasarlo por alto sin cometer un error garrafal, el testimonio de un natural da a entender claramente que era la desgracia lo que motivaba la actitud de los negros. Si robaban a los indios sus escasas pertenencias dentro y fuera del obraje, era porque su dueño no les atendía en sus necesidades más elementales como la comida y la vestimenta: «... se ha entendido que esto lo hacen de hambre y desnudez». Por si fuera poco, la expresión «se ha entendido» sugiere que no se trata de un juicio personal, sino más bien de una opinión compartida por varios y quizá por los responsables de la comunidad indígena, los cuales darían de este modo prueba de discernimiento y de clarividencia. Así que, por muy corta que es, resulta la declaración significativa de la doblez del dueño. No cumplía sus obligaciones para con sus esclavos, seguros de que se las arreglarían a expensas de los naturales cuya pasividad no les resistiría. Nos encontramos pues frente a otra manifestación de lo que llamamos en su tiempo el síndrome de Marcuse ${ }^{39}$. Pero lo interesante es que fue un congénere de las víctimas de los esclavos quien hizo esta comprobación, lo cual le da una dimensión objetiva, y otorga más autenticidad a los dichos de sus coterráneos, incitados a no caber duda por los dominicos a superar sus temores frente al poderoso obrajero. No se puede negar que el procurador de los hermanos predicadores llevó la batuta —al fin y al cabo cumplía con la misión histórica de su orden en las Indias-, pero ello no amengua la verosimilitud de los testimonios de los naturales, numerosos y concordantes pese a algún que otro fallo de memoria. Si los informes que llegaban a la Corona solían hacer énfasis en los «vicios» de los esclavos para

39 Tardieu, 2000. 
explicar sus abusos para con los indios, esta encuesta dirigida por un oidor y efectuada por colaboradores nombrados por él, como consecuencia de la Ordenanza de obrajes de 1664, patentiza la verdadera causa de las tensiones entre los esclavos y los indios de San Ildefonso, a saber, la despiadada codicia del amo, según se puede deducir de dicha declaración. En este sentido, si la leemos detenidamente, la encuesta sale de los tópicos manejados por los defensores de los indios.

El marco concentracionario de los obrajes (no olvidemos la expresión «puertas adentro» empleada a menudo para situar los acontecimientos) exacerbaba primero la desesperanza de los esclavos. No tenían la posibilidad de compensar sus desgracias como ocurría en la ciudad, merced a los jornales, a la benevolencia de los amos conseguida por mediación de la enajenación, o en las haciendas donde se podía mejorar lo cotidiano con, por ejemplo, el trabajo de los conucos o chacras. No les quedaba más recurso que acudir a la violencia en contra de los más débiles, a imitación de los dueños, no tanto por gusto de dominar - incluso en algunos casos podían experimentar cariño por ellos-, aunque con el tiempo no se puede excluir del todo esta evolución, como por la necesidad de sobrevivir, según el principio de que la violencia genera la violencia.

Por añadidura los amos, como don Antonio López de Galarza, vieron la ventaja que podían sacar de esta necesidad de compensación, transformando a los esclavos de obrajes en matones. El matonismo servil patentiza la perversión del sistema de explotación en el sector de producción textil. Lo peor es que dichos obrajeros no conseguían siempre dominar a las quimeras forjadas por su codicia, quienes se hundían en una criminalidad que se solía explicar por la idiosincrasia de los victimarios, cuando manifestaba de un modo desesperado el rechazo de las normas impuestas por la sociedad esclavista.

\section{REFERENCIAS CONSULTADAS}

\section{FUENTES PRIMARIAS}

Archivo General de Indias, Sevilla, Audiencia de Quito 9, R. 7, N. 52, 1, fol. 2v.

Archivo General de la Nación, Quito (Ecuador), sección Obrajes, caja 3, expte 1; caja 4 , expte 1 ; caja 7 , expte 1 ; caja 8 ; caja 9 , expte 3 ; caja 13 , expte 9 ; caja 15 , expte 1; caja 18.

Archivo Histórico del Azuay, Cuenca (Ecuador), Notaría tercera, libro 502. 


\section{BigLIOGRAFÍA}

Alcedo, Antonio de, Diccionario geográfico histórico de las Indias Occidentales o América es a saber: de los Reyes del Perú, Nueva España, Tierra firme, Chile, y Nuevo Reyno de Granada, Biblioteca de Autores Españoles 207, ed. de Ciriaco Pérez Bustamante, Madrid, Edición Atlas.

Agia, Fray Miguel, Servidumbres personales de Indios (1603), ed. de Fray Javier de Ayala, C.S.I.C., 1964.

Andrien, K. J., The Kingdom of Quito, 1690-1830. The State and Regional Development, New York, Cambridge University Press, 1995.

Brines Tyrer, Robson, The Demographic and Economic History of the Audiencia de Quito: Indian Population and the Textile Industry, 1600-1800, Ph. D. diss., University of California at Berkeley, 1976.

Burgos G., Hugo, Relaciones interétnicas en Riobamba: dominio y dependencia en una región indígena ecuatoriana, Quito, Corporación Editora Nacional, 1957.

Costales Peñaherrera, Jaime, «El obraje de San Ildefonso», Tesis de licenciatura, Pontificia Universitaria Católica del Ecuador, Quito, 1975.

Descripción breve de toda la tierra del Perú, Tucumán, Río de la Plata y Chile para el Excmo. Sr. Conde de Lemos y Andrade, presidente del Consejo Real de Indias, Los Cronistas de Convento, Selección dirigida por José de la Riva Agüero, Selección de Pedro M. Benvenutto Murrieta y Guillermo Lohmann Villena, París, 1920.

González Suárez, Federico, Historia General de la República del Ecuador, vol. VII, Quito, Editorial CCE, 1970.

Levillier, Roberto, Gobernantes del Perú. Cartas y papeles. Siglo XVI, t. XIV. El virrey Luis de Velasco. 1596-1600, Madrid, 1921.

Miño Grijalva, Manuel, «La economía de la Real Audiencia de Quito, siglo XVII», Enrique Ayala Mora (ed.), Nueva Historia del Ecuador, vol. 4, Epoca colonial II, Quito, Corporación Editora Nacional / Grijalbo, 1991: 47-103.

Ortiz de la Tabla, Xavier, «El obraje colonial ecuatoriano. Aproximación a su estudio», Revista de Indias 149-150 (Madrid, julio-diciembre de 1977).

Ortiz de la Tabla Ducasse, Javier, Los encomenderos de Quito, 1534-1660, origen y evolución de una élite colonial, Sevilla, Escuela de estudios Hispano-americanosC.S.I.C., 1993.

Recopilación de Leyes de los Reynos de las Indias, Libro VI, Título VIIII, Ley XVIII, edición facsímil coeditada por el Centro de Estudios Políticos y Constitucionales y el Boletín Oficial del Estado, Madrid, 1998.

Rubén Vargas Ugarte s. j., Rubén, Historia general del Perú, t. III (1596-1689), Lima, Carlos Milla Batres, 1966. 
Rueda Novoa, Rocío, El obraje de San Joseph de Peguchi, Quito, Abya Yala / Tehis, 1988.

Salas de Coloma, Miriam, De los obrajes de Canaria y Chincheros a las comunidades indígenas de Vilcashuamán. Siglo XVI, Lima, Sesator, 1979.

Salas de Coloma, Miriam, Estructuras del poder colonial en el Perú. Huamanga (Ayacucho) a través de sus obrajes. Siglos XVI-XVIII, Pontificia Universidad Católica del Perú, Fondo Editorial, 1998.

Silva Santisteban, Fernando, Los obrajes en el virreinato del Perú, Lima, 1964.

Soasti Toscano, Guadalupe, «Los obrajes del pueblo de Chambo. Siglos XVI y XVII. Apuntes para el conocimiento de la industria textil de la Audiencia de Quito», Tesis de licenciatura, Quito, P.U.C.E., diciembre de 1986.

Tardieu, Jean-Pierre, Les Noirs et les Indiens au Pérou (XVIe-XVIIe siècles). Etude d'une politique ségrégationniste, Paris, L’Harmattan, 1990.

Tardieu, Jean-Pierre, Relaciones interétnicas en América, en: José Andrés-Gallego (Coord.), Nuevas Aportaciones a la Historia Jurídica de Iberoamérica, Madrid, Fundación Histórica Tavera, Colección Proyectos Históricos Tavera (I), CDROM, 2000.

Tardieu, Jean-Pierre, El negro en la Real Audiencia de Quito. Siglos XVI-XVIII, Quito, Abya Yala / IFEA / Coopi, 2006.

Terán Najas, Rosemarie; Pazmiño, Rocío, Gómez; Nidia, Rueda, Rocío, La antigua Riobamba. Historia de una ciudad colonial, Quito, Abya Yala / Municipalidad de Riobamba, 2000.

Tyrer, Robson, «The Demografic and Economic History of the Audiencia de Quito: Indian Population and the Textile Industry, 1600-1800», Tesis doctoral, Universidad de California, Berkeley, 1976.

Villalba, Jorge, «Los obrajes de Quito en el siglo XVII y la legislación obrera», Revista del Instituto de Historia Eclesiástica Ecuatoriana, 8 (Quito, 1986): 43-212.

Fecha de recepción: 6 de julio de 2010

Fecha de aceptación: 4 de mayo de 2011 


\section{Blacks and Indians in the San Ildefonso textile mill. Royal Audience of Quito. 1665-1666}

The concentration space of the textile mills in the colonial Andean world aggravated the tension between the indigenous workers and the black slaves. Ignoring the protective legislation issued in favor of the natives, the owners took advantage of the inversion of social values that was widely accepted and the thirst for compensation brought about by the frustrations of slavery, that turned the Indians into «slaves of the slaves», thus turning the blacks of the mill into true servile thugs. We will study the mechanisms of the system and its consequences in the second half of the 17th century through the case of the San Ildefonso mill, located near Ambato, in modern-day Ecuador.

KeY WORDS: Ecuador; Mills; 17th century; Indians; Blacks. 